Proceedings

\title{
Bubble Behavior on Horizontal and Vertical Carbon Anode Surfaces in Cryolite Melt Applying a See-Through Cell ${ }^{+}$
}

\author{
Nikolina Stanic ${ }^{1}$ and Espen Sandnes ${ }^{1, *}$ \\ 1 Department of the Materials Science and Engineering, Norwegian University of Science and Technology \\ NTNU, NO-7491 Trondheim, Norway, nikolina.stanic@ntnu.no \\ * Correspondence: espen.sandnes@ntnu.no \\ + Presented at The First International Electronic Conference on Metallurgy and Metals, 22 February - 07 March, \\ 2021, ONLINE
}

\begin{abstract}
Gas bubble behavior on a carbon anode in a cryolite melt have been studied by visual observation using a see-through cell. The bubble phenomena studied have been growth, coalescence, detachment during electrolysis. Two different anode designs were tested, an anode with a horizontal facing-downwards surface and an anode with a vertical surface. At the horizontal anode it was found that one large bubble was formed by growth and coalescence of smaller bubbles and finally the large bubble detached periodically. For the vertical anode surface a lot of smaller bubbles were formed and detached randomly. The bubble diameter was decreasing with increasing current density for both anodes.
\end{abstract}

Keywords: carbon anode, cryolite melt, bubble behavior; see-through cell

Citation: Stanic, N.; Sandnes, E. Bubble Behavior on Horizontal and Vertical Carbon Anode Surfaces in Cryolite Melt Applying a See-Through Cell. Mater. Proc. 2021 3, x. https://doi.org/10.3390/xxxxx

Published: 22 February 2021

Publisher's Note: MDPI stays neutral with regard to jurisdictional claims in published maps and institutional affiliations.

Copyright: (c) 2021 by the authors. Submitted for possible open access publication under the terms and conditions of the Creative Commons Attribution (CC BY) license (http://creativecommons.org/licenses /by/4.0/).

\section{Introduction}

The primary anode product in Hall-Héroult process is $\mathrm{CO}_{2} / \mathrm{CO}$ gas mixture. Gas present at the anode surface contributes to an increase cell voltage. The extra potential drop in an industrial cell due to present of bubbles is about $0.15-0.35 \mathrm{~V}$ out of a typical total cell potential of $\sim 4.5 \mathrm{~V}$ [1]. To obtain faster gas bubble release slotted anode designs have been introduced. Anode bubble behavior for different anode designs and materials have been typically studied industrially and also in laboratory scale. The current work examines more closely the bubble behavior for anodes typically used to study reaction kinetics and mass transport, anode effect phenomena, current efficiency, carbon quality properties, etc. To study bubble behavior in more detail is of importance because bubble behavior is relevant for all the above-mentioned features. On the horizontal laboratory scale anodes the bubble life cycle is consistent and periodical but with the industrial anodes, typical behavior is less periodic with release of large bubbles [2].

Several researchers [3-7] studied the bubble life cycle which include processes as bubble nucleation, bubble growth, bubble coalescence and bubble detachment on a downward-facing horizontal carbon anode surface applying a transparent cell capturing images from the side openings combined with the observation from above $[3,4]$, side openings [5, 7], and side and bottom openings [6]. It was reported that small individual spherical bubbles were formed at the horizontal anode surface $(\varnothing 9 \mathrm{~mm})$. The bubbles grew and coalesced to form larger bubbles eventually covering the majority of the anode surface $[3,4]$. After reaching maximum size the bubble was sliding toward the edge of the anode where it was detached and rose vertically. After bubble detachment the bub- 
ble-free part of the anode surface was available for a new process cycle of bubbles nucleation, grow, coalescence and detachment. Bubble behavior was also observed on a vertical anode surface only in a few studies. Cassayre et al. [3, 4] studied bubble formation on the verticals side of a graphite anode cylinder at lower current densities $(0.05-$ $0.2 \mathrm{~A} \mathrm{~cm}^{-2}$ ). It was found that bubble nucleation occurs on specific nucleation sites. The number of nucleation sites grew with the increase in current density. Spherical-shaped bubbles grew and coalesced until reaching $2-3 \mathrm{~mm}$ in diameter then detached and escaped vertically. The surface coverage was found to be very high and the small bubbles appeared stuck to the anode.

The aim of the current work was to study bubble formation and detachment for a horizontal (facing downward) electrode surface and a vertical electrode surface. Video recordings during electrolysis using the different anode designs were performed in a see-through cell. Results obtained in this work can not be directly applied to an industrial setting but increased knowledge of the bubble behavior is useful for further improvement of gas release and especially in laboratory scale studies applying these types of anode designs.

\section{Experimental part - Materials and Methods}

\subsection{See-through cell}

The experiments were conducted in the see-through furnace shown in Figure 1(a). In Figure 1(b) is shown a principle sketch of the experimental setup. Video recording was performed from the side. The furnace has two side openings which are closed with lids. The lids are removed and replaced with quartz windows only during video recording in order to reduce heat loss. The quartz crucible was resting at an alumina tower construction which was used to adjust the height level of the crucible. The alumina tower was placed in a ceramic crucible whose function was to catch the bath in case of crucible breakage during the experiment.

(a)

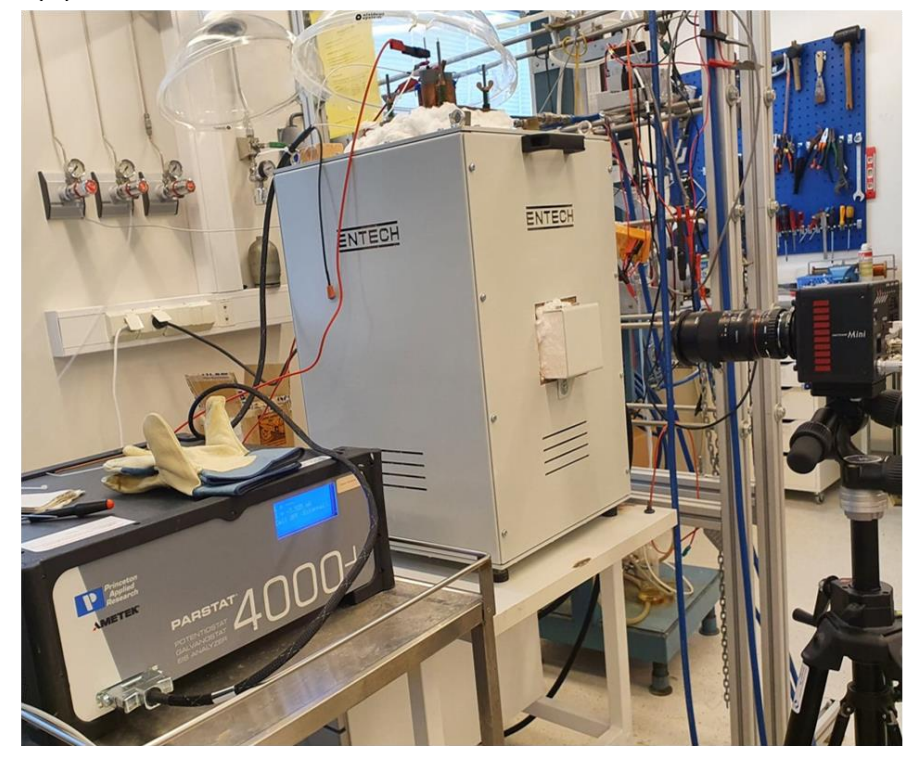

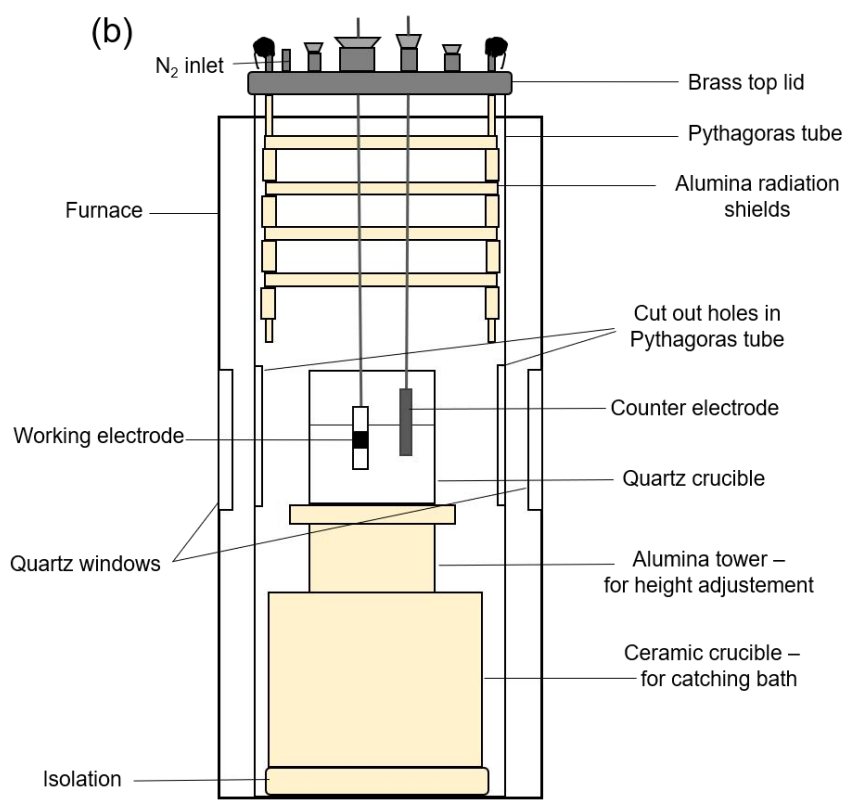

Figure 1. (a) See-through furnace and experimental cell setup, (b) Principle sketch of the interior of the furnace 


\subsection{Bath composition and temperature control}

Experiments were performed in a cryolite bath at a temperature of $890 \pm 10 \mathrm{C}^{\circ}$. The bath composition used in this study is listed in Table 1. The calculated liquidus temperature was $838 \mathrm{C}^{\circ}$ (Appendix A). The superheat was on purpose kept this large in order to avoid bath freeze due to frequent openings of the furnace side lids and to prolong the video recording time. The bath was contained in the quartz crucible with a wall thickness of $2 \mathrm{~mm}$. The crucible lifetime was maximum 5-6 hours including the heating process which took around minimum 2 hours. The quartz crucible normally broke down due to a formation of holes in the quartz wall at the bath meniscus. On heating when a temperature of $890{ }^{\circ} \mathrm{C}$ was achieved the side lids of the furnace were removed and replaced with the quartz windows. After some time (approx. 20-30 minutes) the bath started to freeze on the quartz walls due to heat loss. This was associated with reduction in bath temperature. The quartz windows were removed and replaced with the side lids. If necessary, the set point of the furnace power supply was increased by $5-10{ }^{\circ} \mathrm{C}$. After 15 minutes the side lids were removed and the quartz crucible and bath were checked for transparency in order to continue the experiment.

Table 1. Cryolite bath composition

\begin{tabular}{llll}
\hline & wt \% & Specification & Producer \\
\hline $\mathrm{Al}_{2} \mathrm{O}_{3}$ & 3 & $\gamma$-alumina & Merck \\
\hline $\mathrm{AlF}_{3}$ & 15 & sublimed “in house" & Industrial grade \\
\hline $\mathrm{LiF}$ & 15 & purum & Riedel-de-Haën \\
\hline $\mathrm{CaF}_{2}$ & 5 & precipitated pure & Merck \\
\hline Cryolite & 62 & synthetic, purity $>97 \%$ & Sigma-Aldrich \\
\hline
\end{tabular}

\subsection{Anode design}

Two anode designs, one with horizontal and one with vertical surface, and with the same dimensional length $(10 \mathrm{~mm})$ were applied. The horizontal anode and the vertical anode are shown in Figure 2. Both anodes were made as described in [8]. A purified graphite material (Schunk Tokai Scandinavia, AB, Sweden) was the active electrode material. Boron nitride (BN) (BN5000, Kennametal, UK) was used for anode shielding. The immersion depth of both anodes in the bath was around $3.5 \mathrm{~cm}$. As a counter electrode a stainless steel (SS) rod with diameter $5 \mathrm{~mm}$ was used. The SS rod was immersed around 4 $\mathrm{cm}$ into the bath which gave an area of approx. $6.5 \mathrm{~cm}^{2}$.

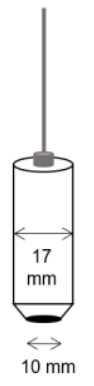

(a)

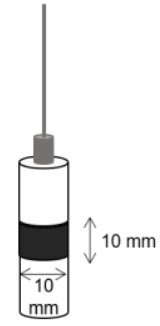

(b)

Figure 2. Anode designs with the same dimensional length of $10 \mathrm{~mm}$; (a) the horizontal anode with surface area $0.79 \mathrm{~cm}^{2} \mathrm{where}$ boron nitride edges were chamfered by an angle of 45 degrees and (b) the vertical anode with surface area $3.14 \mathrm{~cm}^{2}$. 


\subsection{Experimental methods}

Electrochemical measurements were performed using a PARSTAT (Princeton Applied Research) potentiostat and a 20 A booster (KEPCO). A two-electrode system was used. A reference electrode was not applied due to space limitations in the cell and the disturbance of the video image. Electrolysis was performed at constant cell voltage and at constant current. Current vs. time measurements for the horizontal anode were transformed into frequency spectra by using a Fast Fourier Transform algorithm in Sigview software-spectrum and signal analysis. The signals were transformed into the frequency domain to evaluate how the power of the signal is distributed over a range of frequencies to determine dominant frequency. The sampling rate $(\mathrm{Fs})$ was $10 \mathrm{~Hz}$, consequently the spectrum has a frequency range from zero to $\mathrm{Fs} / 2,0-5 \mathrm{~Hz}$.

A Photron Fastcam Mini AX camera was used for the video recording. Two different frame rates were used, $60 \mathrm{fps}$ (frames per second) for the recording of the bubble behavior for both anode designs, and $125 \mathrm{fps}$ was used in addition for the vertical anode. Recording with the higher rate was used in order to be able to capture fast events like coalesence. A Photron Fastcam Viewer 4 (PFV4) software was used for the control of the Photron high-speed camera, data saving, and image processing.

\section{Results and discussion}

\subsection{Bubble behavior on the horizontal anode}

In Figure 3 is shown one bubble life cycle which include the bubble nucleation, growth, coalescence and bubble detachment during electrolysis at constant cell volatge of $1.5 \mathrm{~V}$. The corresponding average current density was $0.4 \mathrm{~A} \mathrm{~cm}^{-2}$. The beginning of the bubble cycle was considered to be when the anode surface is free of a large bubble, which is the situation right after the bubble from the previous cycle is detached, frame (1). It was found that one cycle lasts 328 frames. Since the video recording was obtained with the speed of $60 \mathrm{fps}$, one frame corresponds to $(1 / 60)$ second. Thus, the bubble cycle time was found to be $5.47 \mathrm{~s}$. There was no possibility with the current set up to position the camera to observe the bottom of the horizontal anode straight from below. Therefore, the bubble nucleation and coalescence were difficult to observe. Growth of the bubbles and detachment as one big bubble were well observed from the side. The bubbles grew to a size as large or slightly larger than the horizontal carbon surface before it started to slide toward the edge (frame 325) and was detached (frame 329).

In Figure 4(a) the details of the characteristic saw-tooth curve of the current-time data are shown. When a bubble was detached a sharp jump in current occurred and the current obtained its highest value. When bubbles are nucleating, growing and coalescing the current density decreases almost linear while bubbles are covering more and more of the surface. At the time of detachment of a big bubble the surface is never totally free of bubbles. As can be seen in Figure 3 at frames (1) and (329) the carbon surface is indicated with the red dashed line. While one large bubble is sliding toward the edge to be detached the smaller bubbles are already nucleating and growing at the left part of the anode surface. From frame (329) and to a certain extent frame (1) it can be seen that the bubble layer is thicker on the left side than at the tail of the departing bubble. Bubbles strongly affect the potential components at gas-evolving electrodes. For areas where bubbles almost block the electrode surface the current will be close to zero, but for areas where bubbles do not block the electrode surface the current density is greater than the average [9]. Frame (318) corresponds to the smallest current measured, i.e. when a big bubble almost cover the whole anode surface. Frame (329) corresponds to the highest current value, i.e. the time of detachment of a large bubble. From Figure 4(a) the bubble 
cycle time was found to be around $5.5 \mathrm{~s}$ and is very close to $5.47 \mathrm{~s}$ found from Figure 3 . In Figure $4(\mathrm{~b})$ is shown the FFT analysis of current-time data which gave a dominant frequency of $0.18 \mathrm{~Hz}$ corresponding to a bubble cycle time of $5.5 \mathrm{~s}$. This confirms that the dominant frequency equals the bubble release frequency.
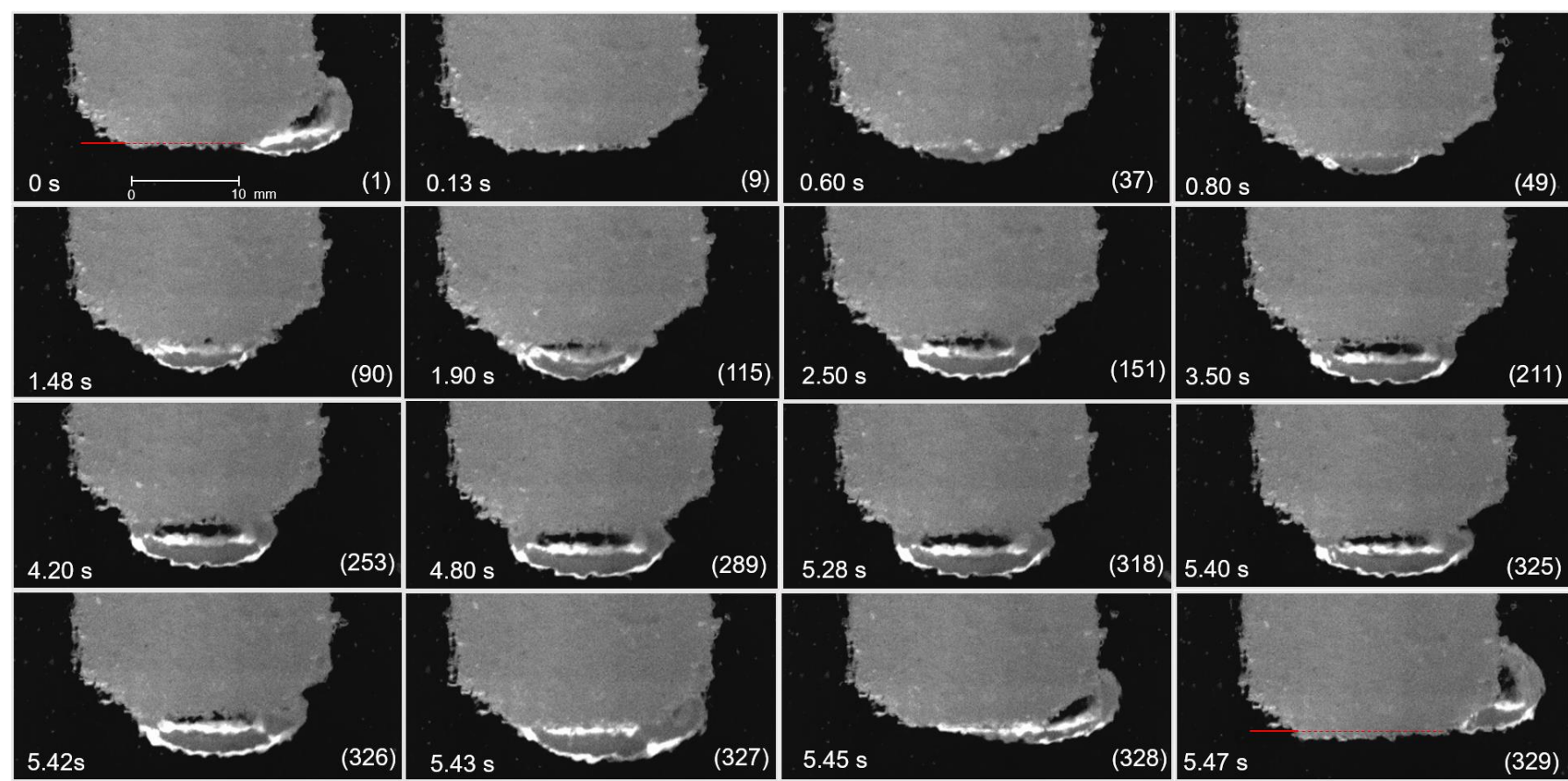

Figure 3. Cycle of one bubble formed and detached from the horizontal surface during electrolysis at a constant cell voltage of $1.5 \mathrm{~V}$ with an average current density of $0.4 \mathrm{~A} \mathrm{~cm}^{-2}$. Frame numbers are given in brackets. The frame rate was $60 \mathrm{fps}$. Frame (1) is defined as 0 second and shows the situation right after a large bubble from the previous bubble cycle is detached from the anode surface. The horizontal dashed red line in frames (1) and (329) represents the vertical position of the carbon anode surface. A scale bar is shown in frame (1) and the bar also indicates the horizontal position of the carbon anode surface.
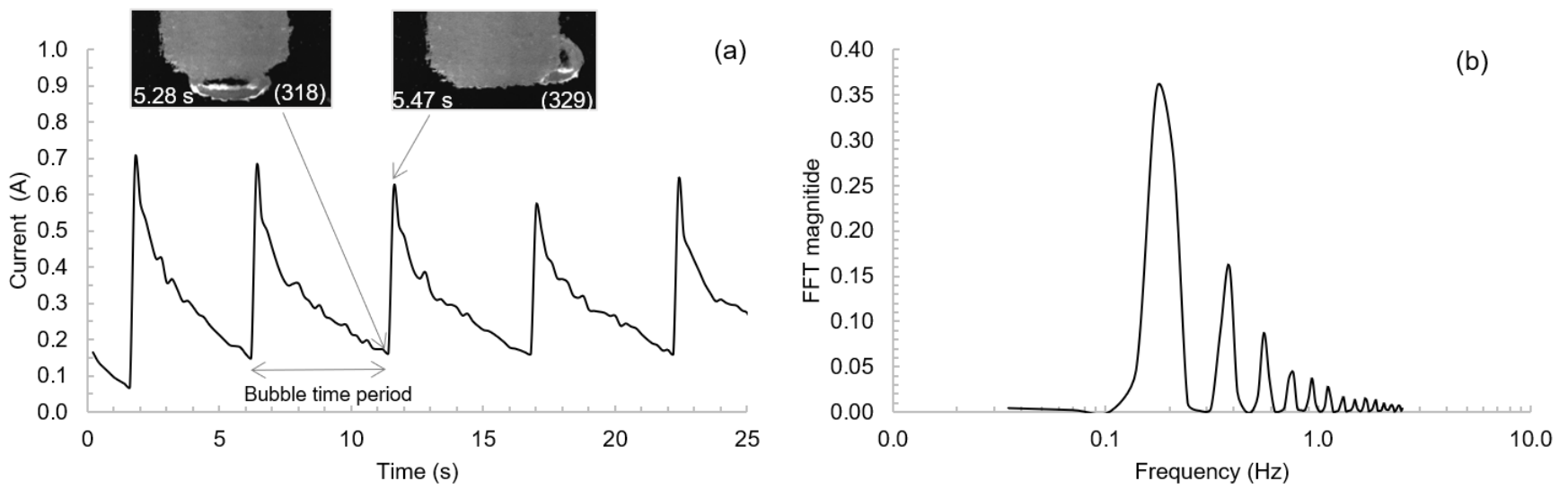

Figure 4. The horizontal anode; (a) Current vs. time data at constant cell voltage of $1.5 \mathrm{~V}$ and details of the saw-tooth curve. Frame (318) represents the situation when the smallest current is measured and frame (329) represents the situation when the highest current is measured. (b) FFT spectra of current-time data.

The thickness of the bubble was determined as the vertical distance between the anode surface and the bubble surface just before the bubble started to slide toward the edge of the anode for its detachment. For the horizontal anode at a current density of $1 \mathrm{~A}$ $\mathrm{cm}^{-2}$ the thickness of the bubble was found to be around $4.6 \mathrm{~mm}$. Most studies suggested that the bubble layer thickness is around $5 \mathrm{~mm}$ in both laboratory and industrial cells [3-5, 10]. Cassayre et al. [4] observed that the bubble layer under a graphite anode ( $\varnothing 9 \mathrm{~mm}$ ) 
was slightly decreasing with current density and its thickness was in the interval $4.2-5.0$ $\mathrm{mm}$ for a current range in the interval $0.2-1.6 \mathrm{~A} \mathrm{~cm}^{-2}$.

The average bubble diameter after bubble detachment from the horizontal surface as a function of current density is presented in Figure 5. The bubble diameter was calculated as an average value of 10 bubbles at each current density. The bubble diameter decreases with increasing current density, from around $7 \mathrm{~mm}$ at $0.25 \mathrm{~A} \mathrm{~cm}^{-2}$ to around $6 \mathrm{~mm}$ at $1 \mathrm{~A} \mathrm{~cm}^{-2}$. Cassayre et al. [3,4] measured the bubble diameter before its detachment from the surface and also found that the bubble diameter decreased with increasing current density. It was explained by less pronounced coalescence at higher current densities and that bubbles escape before covering the anode and grow to full size. Cassayre et al. $[3,4]$ also found that with increasing current density the bubbles became smaller and formed at a higher frequency. An increase in current density and a corresponding increase in potential lead to an increase in the number of nucleation sites, i.e. meaning smaller and a higher number of bubbles are formed. These bubbles coalesce into one large bubble and the bubble cycle time is shorter. Bubble induced convection increases with increasing current density as more bubbles are released from the surface. The increased convection promotes easier detachment of the bubbles and also contributes to formation of smaller bubbles.

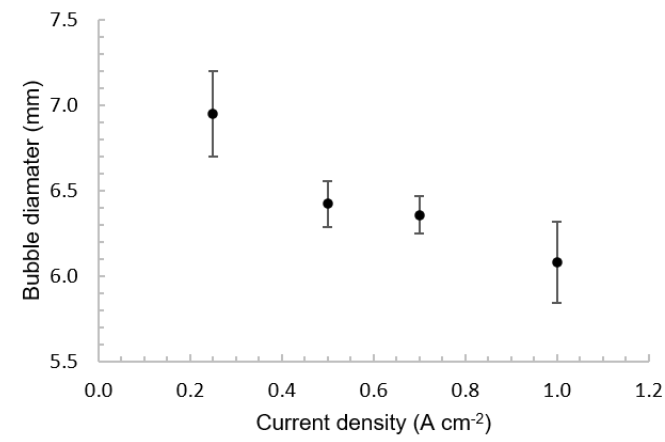

Figure 5. Bubble diameter after detachment from the horizontal surface as a function of applied current density.

\subsection{Bubble behavior on the vertical anode}

The bubble life cycle (nucleation, growth, coalescence, and detachment) at a vertical surface was studied in detail at low current density, $0.1 \mathrm{~A} \mathrm{~cm}^{-2}$, and with a slightly higher frame rate, $125 \mathrm{fps}$. At this current density convection is low in comparison to higher current densities and the transparency of the melt was at its best due to small amount of dispersed bubbles in melt. The images are shown in Figure 6 and Figure 7. The bubble formation occurs at specific nucleation sites. It was not found any periodic pattern in bubble growth and coalescence making the bubble life cycle more a random process. It was observed that some bubbles formed at the surface were coalescing with other bubbles, either with bubbles positioned nearby or with bubbles sliding upwards along the vertical anode surface. It was also observed that some bubbles were not coalescing, either detaching from the surface immediately or resting at the surface for a random time before detaching. It was observed that for the bubble to leave the surface it has to grow to a certain size. The measured diameter of detached bubbles for a current density of $0.1 \mathrm{~A}$ $\mathrm{cm}^{-2}$ was in the range $3.3 \mathrm{~mm}$ to $3.6 \mathrm{~mm}$. If the bubble gets entrapped at the boron nitride/carbon boundary the resting time is radically increased as discussed below in relation to Figure 7. 
In Figure 6 is shown the fast process of coalescence of two bubbles into one bubble and the fast detachment of that bubble. The upper bubble was resting at the anode surface for around $1 \mathrm{~s}$ when a smaller bubble was formed below, frame (1). Both bubbles were growing and the lower bubble was approaching the upper bubble. The diameter of both bubbles was measured in frame (256) and was found to be $2.0 \mathrm{~mm}$ for the upper bubble and $2.5 \mathrm{~mm}$ for the lower bubble. In frame (257) it can be seen that the lower bubble was approaching the upper bubble. Frame (258) represents the intermediate stage in the coalescence process. In frame (259) the new bubble has obtained its final shape. The coalescence process is fast, taking place in about three frames corresponding to 0.024 seconds. The bubble diameter after coalescence was $3.3 \mathrm{~mm}$. Immediately after coalescence the new bubble has gained enough buoyancy to be able to detach from the anode surface. The detachment process starts in frame (260). The bubble is completely detached in frame (263) and the diameter after detachment was $3.4 \mathrm{~mm}$.

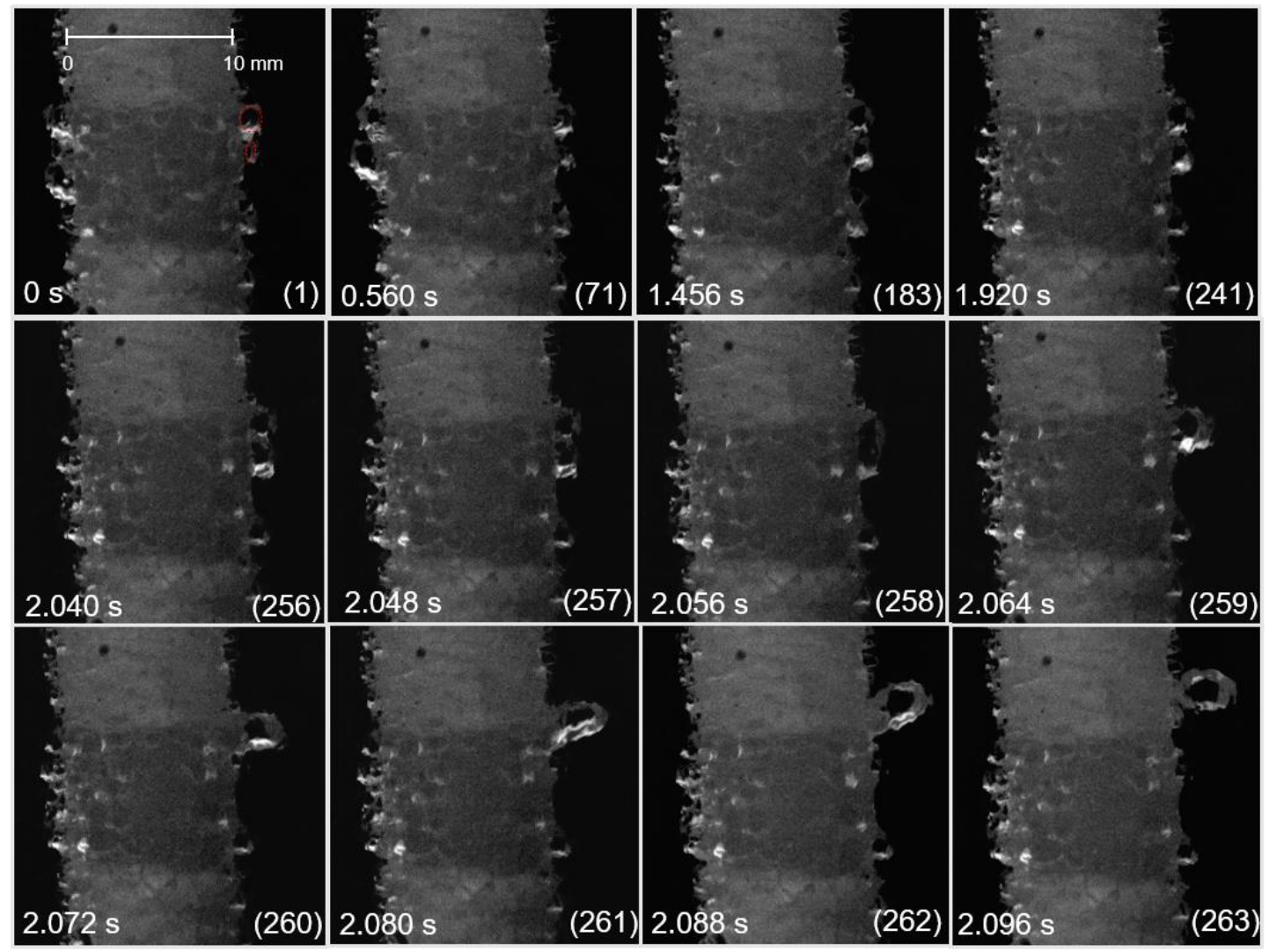

Figure 6. The process of coalescence of two bubbles (marked with red dashed line) into one bigger bubble and its immediate detachment from the vertical surface during electrolysis at a constant current density of $0.1 \mathrm{~A} \mathrm{~cm}^{-2}$. Frame rate was 125 fps. Frame numbers are given in brackets. Frame (1) is defined as 0 second. A scale bar is shown in frame (1).

In Figure 7 is shown the fast process of coalescence of three bubbles into one bubble. The diameter of three bubbles was measured to be around $1.5 \mathrm{~mm}$, frame (1). Frame (3) represents the intermediate stage in the coalescence process. In frame (4) the new bubble has obtained its shape and a diameter of $2.7 \mathrm{~mm}$. The coalescence process is fast, taking place in about two frames corresponding to 0.016 seconds. After coalescence the bubble was resting and growing at the boundary between boron nitride $(\mathrm{BN})$ and carbon anode (C). The bubble detachment is observed in frame (295) where the bubble is rising. The bubble diameter after detachment was $3.3 \mathrm{~mm}$. The long resting of the bubble at the BN/C boundary could be explained by the work of Åsheim et al. [11] who predicted that 
gas bubbles can be entrapped at the boundary due to better wetting of the $\mathrm{BN}$ by the cryolite in comparison to carbon. Probably such a bubble needs extra time to grow to a certain size because it is in the contact with the BN. It probably also needs to grow bigger in size to be able to detach. However, no clear evidence for this was found because the size of the bubbles was in the same size range as bubbles detached from other places on the carbon surface.
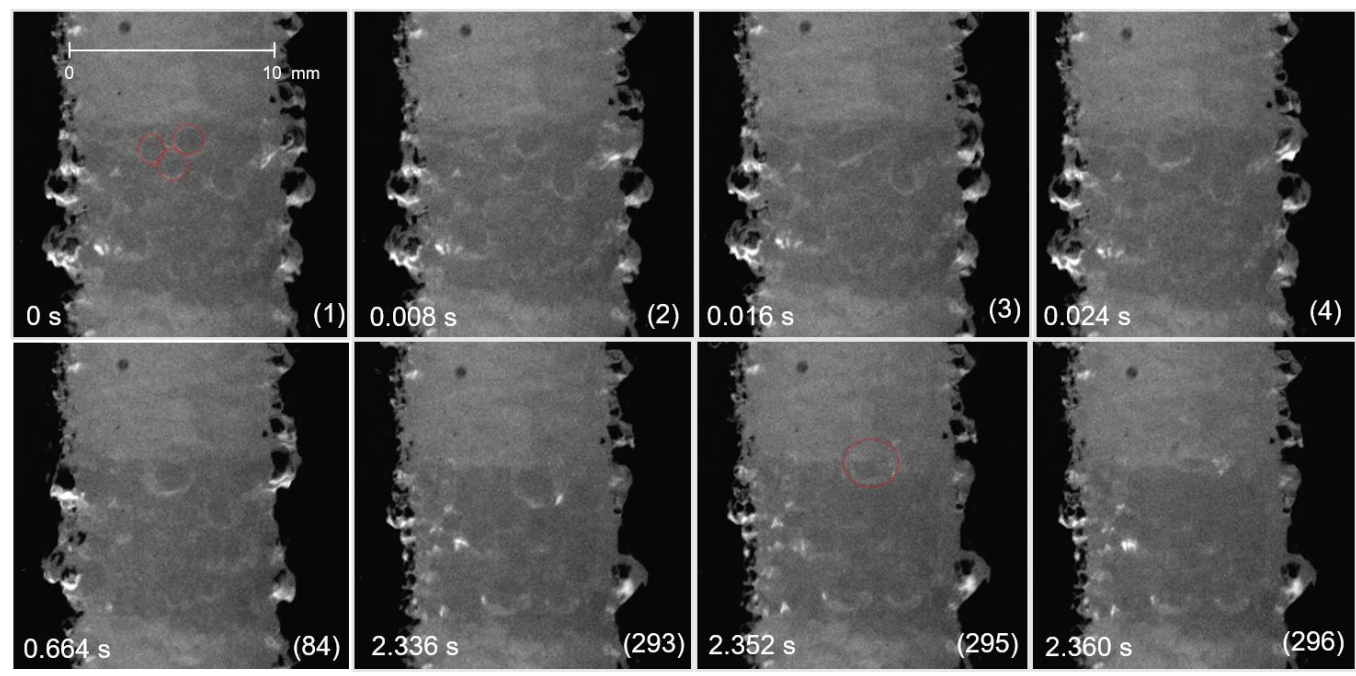

Figure 7. The process of coalescence of three bubbles (marked with red dashed line) into one larger bubble and its entrapment at the boundary between $\mathrm{BN}$ and $\mathrm{C}$ during electrolysis at a constant current density of $0.1 \mathrm{~A} \mathrm{~cm}^{-2}$. Frame rate was 125 fps. Frame numbers are given in brackets. Frame (1) is defined as 0 second, indicating the start of the coalescence process. A scale bar is shown in frame (1).

The average bubble diameter after detachment from the vertical surface as a function of current density is presented in Figure 8. It was calculated as an average value of 10 bubbles at each current density. The bubble diameter is decreasing with increasing current density, from around $3.5 \mathrm{~mm}$ at $0.1 \mathrm{~A} \mathrm{~cm}^{-2}$ to around $2 \mathrm{~mm}$ at $1.7 \mathrm{~A} \mathrm{~cm}^{-2}$. The increase in current density and thereby the corresponding increase in potential give higher driving force for nucleation of relatively more bubbles. The bubble induced convection is more efficient for the vertical anode than for the horizontal anode due to the smaller bubbles formed on the vertical anode as well as the bubble rising along the vertical surface. The larger flow makes bubble detachment easier.

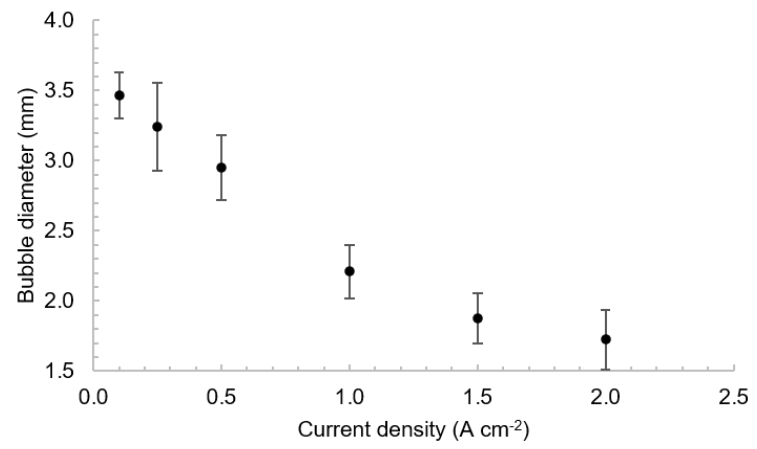

Figure 8. Bubble diameter after detachment from the vertical surface as a function of applied current density. 


\section{Conclusions}

The bubble diameter decreased with the increasing current density for both the horizontal and the vertical anode. Explanations for these observations are the larger number of nuclei formed at higher potential and the more efficient bubble induced convection.

At the horizontal facing downwards surface the bubbles grew and coalesced to form one large bubble which then grew larger and finally started to slide toward the edge of the anode surface for detachment. Even though the big bubble detached the surface was never free of bubbles for the current density of $0.4 \mathrm{~A} \mathrm{~cm}^{-2}$ studied.

At the vertical anode surface a lot of smaller bubbles were formed and detached randomly. Coalescence of two and three bubbles into one bigger bubble was observed on the vertical anode surface. The coalescence process happened quite fast, in about $20 \mathrm{~ms}$ from initiation to the final bubble shape was established. Some intermediate stages in the coalescence process were captured.

Author Contributions: Nikolina Stanic performed all the experimental work and wrote the manuscript. Espen Sandnes supervised the work.

Funding: The research was funded by the Norwegian University of Science and Technology, NTNU.

Conflicts of Interest: The authors declare no conflict of interest.

\section{Appendix A}

For this study applying a see-through cell it was crucial to introduce additives to the cryolite based bath in order to reduce the liquidus temperature and with it to increase the service time of the quartz crucible. The following empirical equation was used for the calculation of the liquidus temperature [12]:

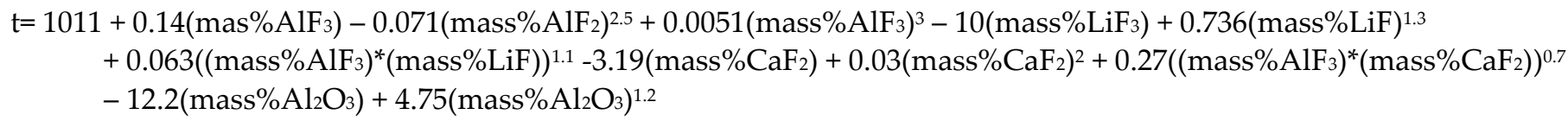

Equation (A1) agrees reasonably with other literature data [13].

\section{References}

1. Zhao, Z., Z. Wang, B. Gao, Y. Feng, Z. Shi, and X. Hu. Observation of Anodic Bubble Behavior Using Laboratory Scale Transparent Aluminium Electrolysis Cells. in Light Metals 2015, ed. M. Hyland, (Cham: Springer, 2015), 2015, p. 801-806.

2. Einarsrud, K.E. A Treatise on Interpolar Transport Phenomena. Doctoral Thesis. NTNU, Trondheim, Norway, 2012

3. Cassayre, L., T. Utigard, and S. Bouvet. Visualizing gas evolution on graphite and oxygen-evolving anodes. JOM (USA), 2002. 54(5), p. 41-45.

4. Cassayre, L., G. Plascencia, T. Marin, S. Fan, and T. Utigard. Gas Evolution on Graphite and Oxygen-Evolving Anodes During Aluminium Electrolysis. in Light Metals 2006, ed. T.J. Galloway, (Warrendale: TMS, 2006), 2006, p. 379-383.

5. Xue, J. and H.A. Øye. Bubble behaviour : cell voltage oscillation during aluminium electrolysis and the effects of sound and ultrasound. in Light Metals 1995, ed. J. Evans, (Warrendale: TMS, 1995), 1995, p. 265-271.

6. Zhao, Z., Z. Wang, B. Gao, Y. Feng, Z. Shi, and X. Hu. Anodic Bubble Behavior and Voltage Drop in a Laboratory Transparent Aluminum Electrolytic Cell. Metall. Mater. Trans. B, 2016. 47(3), p. 1962-1975.

7. Huang, Y., Z. Wang, Y. Yang, B. Gao, Z. Shi, and X. Hu. Anodic Bubble Behavior in a Laboratory Scale Transparent Electrolytic Cell for Aluminum Electrolysis. Metals, 2018. 8, p. 806. 
8. Stanic, N., I. Jevremovic, A.M. Martinez, and E. Sandnes. Bubble Evolution on Different Carbon Anode Designs in Cryolite Melt. Metallurgical and Materials Transactions B, 2020. 51(3), p. 1243-1253.

9. Leistra, J., P. Sides, and J. Leistra. Hyperpolarization at Gas Evolving Electrodes. II. Hall/Heroult Electrolysis. Electrochim. Acta, 1988. 33(12), p. 1761-1766.

10. Cooksey, M., M. Taylor, and J. Chen. Resistance due to gas bubbles in aluminum reduction cells. JOM (TMS), 2008. 60(2), p. 51-57.

11. Åsheim, H., I.A. Eidsvaag, A. Solheim, H. Gudbrandsen, G.M. Haarberg, and E. Sandnes. The Influence of Polarisation on the Wetting of Graphite in Cryolite-Alumina Melts. in Light Metals 2020, 2020. Cham: Springer International Publishing, p. 608-619.

12. Grjotheim, K. and H. Kvande: Introduction to aluminium electrolysis : understanding the Hall-Héroult process. 2nd ed. 1993, Düsseldorf: Aluminium-Verlag, p. 147-158.

13. Haupin, W. The Liquidus Enigma. in Light metals 1992 : proceedings of the technical sessions presented by the TMS Light Metals Committee at the 121st TMS Annual Meeting, San Diego, California, March 1-5, 1992, ed. E.R. Cutshall, (Warrendale, Pa: Minerals, Metals \& Materials Society, 1991), 1991, p. 477-480. 